\title{
Research on Industrial Transformation and Upgrading and technological innovation of Cultural Manufacturing Industry Taking Deqing Piano Industry as Example
}

\author{
Yu Xiaohan ${ }^{* 1, a}$ Wu Huidan ${ }^{2, b}$ \\ ${ }^{1}$ School of Marxism, Ji'nan University, Guangzhou, China \\ ${ }^{2}$ School of Finance \& Economics, Zhejiang University, Hangzhou, China
}

\begin{abstract}
This paper takes the piano industry of Deqing County as example, under the framework of technological innovation and industrial transformation and upgrading model, demonstrates from four levels including technology, talents, entrepreneurs and government behavior, and analyzes the difficulties and suggestions of technological innovation and industrial transformation and upgrading.
\end{abstract}

\section{Research background}

With the acceleration of the process of world economic integration and the exponential growth of science and technology, change has gradually become the primary source of corporate competitive advantage. In 2017, the added value of China's cultural manufacturing industry was 1105.3 billion yuan, accounting for $40.6 \%$ of the added benefit of culture industries. The aggregate is enormous, but the cultural manufacturing industry is still in the stage of low significance development, that the quality is not high, and the brand effect is insufficient. It is difficult to adapt to the market competition with the older model. Only through continuous technological innovation can it maintain a comparative advantage in the market competition. On the other hand, due to the inherent externalities and uncertainties of technological innovation, government actions make up for this shortcoming. In terms of market supervision and policy support, the government has unique advantages that companies cannot substitute to balance the interests of enterprises of different scales and to promote the coordinated and orderly development of technological innovation in large and medium-sized enterprises, which are the critical factor for the vitality of technological innovation. In the process of further development of the cultural manufacturing industry to high levels, all-round, and new forms of industry, technological innovation and government actions have become a vital source of power for improving its overall competitiveness.

\section{Research on technological innovation of the cultural industry and government behavior}

Since 1912, Joseph Schumpeter put forward "innovation" and its role in economic development for the first time, research on innovation has exceeded a hundred years of history. Enos (1962) first clearly defined technological innovation as the result of a combination of several behaviors, including the choice of invention, capital investment guarantee, organization establishment, plan making, recruiting workers and developing markets ${ }^{[1]}$.

Technological innovation has laid the foundation and promoted the development of global cultural industries. The research on the impact of technological change on cultural industries mainly comes down to two aspects: efficiency and mode of production. On the efficiency level, Caves explained the development of new technologies will promote new products and services to be continuously updated and upgraded and gain more favor from consumers ${ }^{[2]}$. The shortening of the technological innovation cycle will accelerate the drastic shortening of the period of cultural business development, such as the internal demand for survival competition among various cultural formats will promote the development of scientific and technological innovation; and the impact of scientific and technological innovation on cultural formats will persist throughout the evolution of cultural formats (Zheng Suxia,2009) ${ }^{[3]}$.

Acquiring technological innovation and development requires the use of government forces. The externality of public goods and market failures led to the insufficiency of technological innovation investment that depended on the market system (S. Martin \& John T. Scott,2000) $)^{[4]}$. Teubal (2002) put forward the standards of the government's technological innovation policy formulation from the theoretical level ${ }^{[5]}$. Technological innovation policies can effectively promote economic development (Aghion,2009; Zhu Pingfang,2003) ${ }^{[6]}$. The most critical policy is the support for talents $\left(\right.$ Mani,2002) ${ }^{[7]}$. 


\section{Research framework}

Based on the above content, this work combines the endogenous factors inherent in technological innovation and government actions and proposes a framework for researching technological innovation in cultural manufacturing, including four main dimensions: technology, talent, entrepreneurs, and government, as shown in Figure 1.

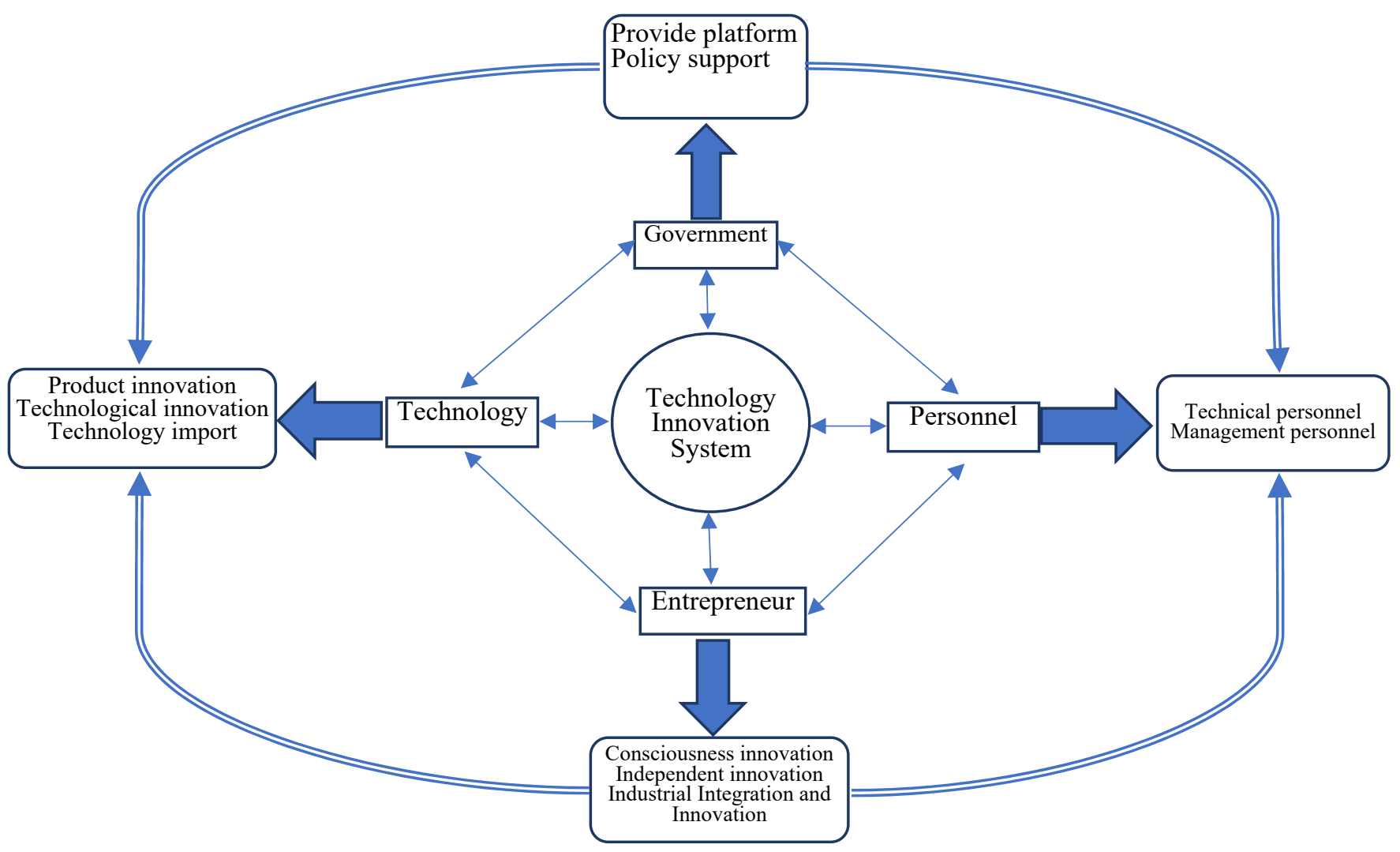

Figure 1 Framework of technological innovation and Industrial transformation and upgrading in the cultural manufacturing industry

\section{Case study - Deqing County piano industry}

The piano industry in Deqing County, Zhejiang Province has a history of more than 30 years and is a typical characteristic of the blocky economy in the Zhejiang model. There are 46 piano manufacturing and accessories companies in Deqing County, including eight large enterprises. The total output value of the piano industry exceeded 470 million yuan, with an annual output of more than 40,000 pianos, accounting for about oneeighth of the country's total piano production, and employing more than 3,000 people. The concentration of industry, high degree of specialization, and complete industrial chain are distinguishable from other regions. Formed in the Luoshe Town and surrounding businesses gathered together, with the economic advantages of the specialization of the economic community, is the largest piano manufacturing center in the Yangtze River Delta region.

However, the current Deqing Piano lacks sufficient market awareness, such as that there is not enough product differentiation and well-known brands, senior core components still need to be imported, and there are only 200 professional and technical personnel. Technological innovation will become a significant way for the piano industry to get rid of the single development model after achieving the desired accumulation. It may even restructure the piano industry, adjust the structure and layout of the piano industry, and accelerate the overall development of the piano industry.

\section{A. Field research and information collection}

This research cooperates with Deqing Piano Manufacturing Association. With the help of the association and various enterprises, we studied the technological innovation status of large and mediumsized piano enterprises in Luoshe Town, Deqing County. The determination of sample companies adopts a combination of the recommendation of the piano industry association and a random selection, so that companies of different sizes, different types of operations and different development situations are involved as much as possible to ensure the scientificity and typicalness of sampling. In 
terms of survey methods, the primary method of visits was to conduct interviews and questionnaire surveys with senior management of the company, focusing on the technological innovation of the company and in-depth and open exchanges with the government. The total number of piano companies and piano components companies in Deqing Luoshe piano is 70 , including 5 piano companies and 40 piano component companies, which consists of 12 manufacturers of piano shell, 8 manufacturers of piano mark, 5 manufacturers of piano hammer, 3 manufacturers of piano string, 6 manufacturers of piano keyboard and 6 manufacturers of piano core. The object of this questionnaire interview is the senior leaders of large and medium-sized piano enterprises. Representatives of some typical piano companies were selected: Zhejiang Leyun Piano Co., Huzhou Huapai Piano Manufacturing Co., Ltd., Huzhou Jieshide Piano Co., Ltd., Deqing Luoshe Auman Piano Factory, Deqing County Outlet Piano Factory, Deqing County Rhythm Piano Co., Ltd., Deqing Luoshe Jinfengsheng Piano Parts Factory and Deqing Luoshe Tianzhi Piano Parts Factory.

\section{B. Deqing piano enterprise technical innovation}

In recent years, the Deqing County government has attached great importance to the improvement of the technological innovation capability of piano enterprises and adopted a series of support measures such as participating in musical instrument exhibitions and holding piano culture festivals.

Firstly, corporate Research and development (R\&D) capabilities and innovation projects have continued to increase. As a traditional manufacturing industry, the piano has a very complex and meticulous process of production. A piano consists of more than 8,000 parts and components and has more than 300 production processes. High-quality professional and technical personnel are engaged in product research and development. Fundamental and scientific research funding is a crucial guarantee for product R\&D. The timely update of product and process design is critical support for the development of piano companies.

Secondly, the technological innovation of piano companies has produced significant economic benefits. Most piano enterprises in Deqing County actively engage in technological innovation and plan their future development. $85 \%$ of the piano business operators are optimistic about the future development of the piano industry and are confident to continue to develop. $90 \%$ of the companies have set development plans for the next three years. For example, Zhejiang Yue Yun Piano Co., Ltd. based on the advantages of this company and Austria K. Clara piano company to create a new piano production line production Kravik piano, continue to broaden the foreign market, increase investment in product research and development, and actively develop innovative projects. In 2017, it invested 2 million yuan, and in 2018 increased to 3 million yuan. There are nine patent projects and 50 million new product sales, ranking first in the county.
Thirdly, the demand for technological innovation of enterprises continues to increase. Most companies actively seek professional and technical personnel to provide innovative projects that are suitable for the development of the company and nurture technological innovation R\&D teams. For example, Deqing Luoshe Jinfengsheng Piano Parts Factory established independent research and development trio, responsible for product development, process improvement, equipment maintenance, and later product quality inspection. In 2017, they developed semi-automatic production equipment for string chords. In 2018, they developed automatic string winding production equipment and applied for patent technology. With the support of automated production methods, they realized a technical income of 7.8 million yuan. Sales of 10 million yuan.

\section{Analysis of Technological Innovation and Government Behavior Patterns}

\section{1) Technology: "Double Creation and One Lead" Model}

Deqing Piano Enterprise has carried out different breakthroughs and developments in terms of technology, and the cycle of product innovation has been getting shorter and shorter. From the very beginning, the piano manufacturing industry has been exploring and learning to design and develop the piano for only five years. The goal of product development is increasing. Pianos are sold to the international market, and the quality requirements for products are progressively increasing. Product R\&D is also developed from singleness to diversification and serialization. This article summarizes it as a "Double Creation and One Lead" model, "Double Creation" means the product innovation and the process innovation, "One Lead" refers to the introduction of technology.

Research shows that many parts of Deqing Piano have adopted different high-precision $\mathrm{CNC}$ automation equipment to ensure the accuracy of the processing of the piano core parts. It also provides comfortable and sensitive playing touch for performers. This means that the realization of technological innovation makes piano companies bid farewell to the era of the traditional handmade piano.

On the other hand, technological innovation is also a direct impetus to the development of corporate technological innovation. From the perspective of the specific practice of the Deqing Piano Enterprise, only the production factors such as capital and technical personnel can be re-optimized and combined through technological innovation.

Technology introduction is an integral part of achieving technological innovation. Technology introduction includes the introduction of proprietary technologies, process flows, and machinery and equipment. The introduction of technologies can improve resource utilization, product quality, and production efficiency. The introduction of technology is the beginning of product and process innovation for 
enterprises. The improvement of technological capabilities and upgrades of technological innovation paths are the twin engines for enterprises to realize the development of technological innovation. This article summarizes the relationship between the three technologies as a "Double Creation and One Lead" model, as shown in Figure 2.

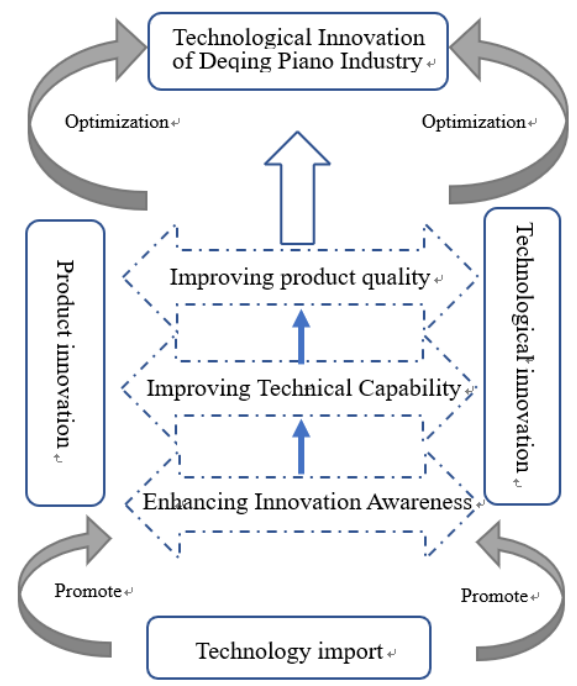

Figure 2 "Double Creation and One Introduction" model

2) Personnel: Technology + Management Mode

Currently, the town has 58 senior piano titles, more than 200 junior professional technicians, and a large number of professionally skilled personnel and skilled workers.

Observing from the academic qualifications of the Deqing Piano Company, the highest academic qualifications are undergraduates, but very few. Academic qualifications are mainly secondary school and high school and below. Many entrepreneurs in the research process stated that the piano industry is different from other high-tech industries. Although the technical requirements are also very high, enterprises in the piano manufacturing field lean more towards talented individuals rather than academically qualified individuals. The demand for talents of most piano enterprises is mainly concentrated in two large blocks. The first is the professional and technical personnel; the second is the management talents. In the field of piano production, the master-pupil transmission is the leading method, that is, the master teacher brings in new apprentices. After a period of training, the apprentices acquire professional skills, and professional and technical personnel are continuously increased through the "mentoring system." The management talents are responsible for the overall process of piano production. Usually, each workshop has a workshop director as a production manager. The management team is generally composed of old employees who are adequately skilled and experienced.

Regular technical guidance from foreign technical experts has promoted the development of technological innovation in the piano industry in Deqing to a certain extent. However, there are few high-level professional and technical personnel, and there are only two or three senior technicians in large scale piano companies. There is only one professional technician in Luoshe.

3) Entrepreneurs: "Three-innovation and codrive" model

Through in-depth interviews, the study attributed entrepreneurs' preference for technological innovation into three types: cognitive innovation, industrial integration innovation, and independent innovation. On this basis, an entrepreneurial "three-innovation and parallel drive" model was constructed, as shown in Figure 3.

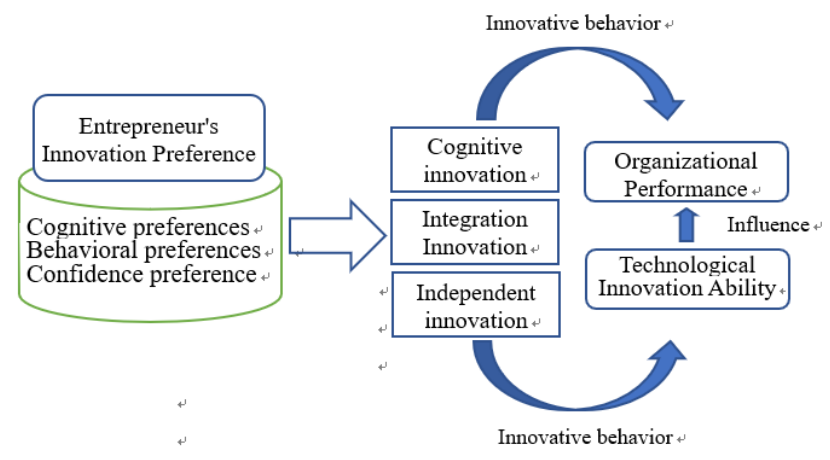

Figure 3 Entrepreneur's "Three Creations" model

Technological innovation is conceptual innovation in itself. The first step is to carry out technological innovation, starting with cognitive innovation, or under the guidance of cognitive innovation ${ }^{\mathrm{i}}$. With continuous learning of advanced production technology at home and abroad and exchanges with professionals in the same industry, many entrepreneurs are also gradually realizing the importance of bold innovation of their own cognition for the development of the company.

As a typical private cultural block in Zhejiang, the Deqing Piano Industry has formed a regional industrial cluster, but the industry scale and standardization operation are still not standardized. To this end, some business owners propose combining technological innovation with industrial integration.

Independent innovation is an innovative behavior in which companies develop new technologies through their efforts, apply new technologies to the production process, increase production efficiency, and obtain economic profits.

\section{4) Government: platform + policy model}

Deqing Luoshe piano is a township-level industry. The scale of the company is different. To ensure that as many companies as possible can receive government support, the government has adopted a series of measures. For example, it led the seven piano culture festivals in succession and led piano enterprises to participate in various musical instrument exhibitions collectively. In the form of "China Piano Music Valley," the piano industry base is planned in a unified manner, and the Deqing Piano Cultural Industry Park is established based on piano production. Besides, the local government has also adopted appropriate economic measures to give enterprises corresponding subsidies, such as tax incentives and financial incentives. 


\section{Problems in technical innovation in Deqing piano industry}

\section{A. Lack of technological breakthrough}

Looking at the development history of the Deqing Piano Company for more than 30 years, the piano production technology has indeed achieved a qualitative leap and development, from the creation of the piano's initial "learning piano" to "independent piano making" and from the traditional "handmade piano." "To the semimanufactured piano," innovation and development have been achieved in terms of products, technology, and technology. However, this is only a longitudinal comparison of Deqing's self-development. It is established, observing the entire Chinese piano industry, that the Deqing piano still has a big gap in production technology compared to some of the largest piano companies in the country. Their standard features are as early as in the early 21 st century. It began to introduce advanced foreign technology and production technology.

During the interview, many enterprises showed that one of the main obstacles in technological innovation is the immaturity of the technology. Enterprises have indeed improved their production efficiency and economic benefits by introducing advanced production technology and process. However, due to the lack of attention to the absorption and innovation of the introduction of advanced technology, many enterprises will repeat or even blindly introduce various equipment every year, resulting in unnecessary waste of resources, but also to a certain extent, inhibit the improvement of technological innovation capabilities of enterprises.

A common problem for many piano entrepreneurs in Deqing is many entrepreneurs believe that piano production as a traditional manufacturing industry, its development is completed by pure manual production, and some processes are unable to achieve mechanized production. However, compared with many large piano enterprises in China, they introduced advanced production technology and production technology from abroad as early as ten years ago, which shows that the automatic production process of a piano can be realized. Most piano enterprises in Deqing have only completed the introduction and use of advanced technology, but have not internalized, re-developed, and innovated the imported technology, forming a processing mode in line with their enterprises. Fundamentally speaking, there is a lack of a mechanism for the second development of advanced technology into enterprise innovation technology.

\section{B. Lack of talent resources}

Talents are the new bottleneck of technological innovation and development in the Deqing piano industry. There are insufficient scientific and technological personnel, limited R\&D personnel, and a severe brain drain. The younger generation studying abroad are not willing to return home to engage in the piano industry.
More than $90 \%$ of piano entrepreneurs said that there was a shortage of talents. Moreover, many enterprises adopt the production mode of digital control technology, and the demand for exceptional talents is increasing.

\section{Inadequate innovative action of entrepreneurs}

The interview shows that entrepreneurs mostly stay at "thinking" level for technological innovation, affirming the decisive role of technological innovation in enterprise development, but the similar technological innovation behavior is insufficient, the mentality is relatively satisfied with the status quo, and the spirit of bold innovation is lacking. Many Entrepreneurs in the piano industry believe that the current development of enterprises has been in a stable period, the development of technological innovation is a massive long-term project, needs more material and financial resources increase the production cost of a piano.

The preferences of entrepreneurs for technological innovation mainly include universities, scientific research institutes, piano industry associations, government, and third-party innovation platforms, among which the most choice is piano industry associations. Deqing Piano Industry Association will hold an industry exchange on the 18th of each month; secondly, for the government, enterprises have developed technological innovation. Chengzhong government has provided a development platform for many times; once again, for universities and scientific research institutions, experts and scholars from many universities and scientific research institutions often visit different enterprises and factories for Industry Exchange and guidance; finally, it is a third-party innovation platform, and only one enterprise has selflearning through professional websites.

\section{The government supports vacancy}

Generally speaking, the government does not attach enough importance to the technological innovation of small and medium-sized enterprises. Large-scale enterprises tend to enjoy more preferential policies, while small-scale enterprises are easy to be ignored. The government's policy support for technological innovation of enterprises does not match the needs of enterprises adequately. The entrepreneurs express that the industry information is inadequate and hope that the government can broaden access to information.

\section{Discussion and Conclusion}

\section{A. Enhance the ability of technology research and development, and increase the intensity of technology import.}

Technological innovation and technological $R \& D$ are inseparable. In order to enhance the technological R\&D capability of cultural manufacturing industry, firstly, one is to set up scientific research and development 
institutions within manufacturing enterprises, which aim to carry out product $\mathrm{R} \& \mathrm{D}$, process $\mathrm{R} \& \mathrm{D}$, equipment maintenance and quality inspection, developing production technology according to the production needs of enterprises, and transforming technology into technology. Second, Innovative achievements do a good job in the management of the technology R\&D process, technology R\&D personnel need to be responsible for the completion of the project as planned, following the completion of the final project, supplemented by the corresponding reward and punishment mechanism. Thirdly, we should learn from the advanced operational experience of the industry, fully cooperate with the excellent enterprises in the industry in technology, and make use of each other's technological talents and R\&D strength to achieve common progress and development in the field of technological innovation.

\section{B. Interaction between Internal Training and External Introduction of Talents}

Through technological research and development, technological innovation and production practice, we can cultivate internal technological talents, broaden the channels of talent cooperation, establish the training mode of technological innovative talents with the integration of industry and education and schoolenterprise cooperation, construct the platform of cooperation between enterprises and universities, form the networked cooperation mode of technological innovation, and realize the resources of technology and talents. We will improve the mechanism for the introduction of innovative technological talents, introduce specialized technical teams, learn from the rich international experience, lead the technological innovation of cultural manufacturing industry to develop further, strengthen international exchanges, and attract experts through market advantages to communicate and exchange, and seek common opportunities for cooperation. Increase the incentive for innovative technological talents, the government and enterprises jointly set up a special fund for innovation incentives to provide higher-level learning opportunities for innovative technological talents.

\section{Remodeling entrepreneurial innovation cognition and action matching}

The entrepreneurial awareness of innovation is the ideological foundation for the development of technological innovation. Entrepreneurs need to conscientiously overcome the arrested development of ideas, break through the conservative nature of ideas, and regard technological innovation and industrial upgrading as the most important tasks for enhancing the economic efficiency of enterprises. Constantly update their knowledge, explore and master the general laws of technological innovation and the specificities of specific technological innovation activities. Emphasize technological innovation planning, analyze and plan the paths that are conducive to the development of technological innovation, and constantly updates and optimizes in practice. Deeply integrate management innovation, starting from the three aspects of organizational management innovation, institutional management innovation, and technical management innovation, and they are related to each other, and work together.

\section{Give play to the government's diverse governance and service capabilities}

Government behavior affects all elements in the technological innovation system. It can be carried out in three levels: innovation environment construction, policy development, and platform construction. Cultivating a good environment for innovation is the main way for the government to promote innovation. Local governments need to follow the trend of development integration, guide, protect and support enterprise development technological innovation from the aspects of technical services, talents, policies, and funds, and create a good innovation environment and broad development space for technological innovation and development of cultural manufacturing enterprises. It is necessary to improve laws and regulations concerning the protection of intellectual property rights as a guarantee for the system to ensure technological innovation results can be successfully transformed into actual productivity.

It is necessary to give full play to the role of government in guiding and supporting enterprise technology innovation, including fiscal and taxation policies, financial policies, and science and technology policies that encourage corporate technological innovation. Establish innovative risk investment funds, actively guide social funds to consciously participate in equity investments in the field of cultural products, provide technological innovation services, fully consider financing needs, and optimize approval procedures.

Learn from the successful experience of foreign countries, carry out the construction of public technology innovation platform, provide information consulting services and technical services for enterprise technological innovation, and establish a resource sharing service window.

To sum up, the transformation and upgrading of China's cultural products manufacturing industry needs the construction of technological innovation, human resources, entrepreneur guidance and policy support, among which technological innovation plays a decisive role. Deqing piano industry, which has a history of more than 40 years, will also usher in new development through transformation and upgrading.

\section{Acknowledgment}

Project supported by Ministry of education's humanities and social sciences research program in 2019, The Research on public cognition of digital museum, 19YJA870016. 


\section{REFERENCES}

1. J.L. Enos, 1962. Invention and Innovation in the Petroleum Refining Industry, NBER Chapters, in: The Rate and Direction of Inventive Activity: Economic and Social Factors, 299-322, National Bureau of Economic Research, Inc.

2. Caves R., 2000. Creative Industries: Contracts between Art and Commerce[M]. Cambridge: Harvard University Press.

3. Zheng S.X., 2009. The Evolution of Scientific and Technological Innovation and Cultural Business Form. Henan Social Sciences, 3, 105-107.

4. Martin S. and Scott J.T., 2000. The Nature of Innovation Market Failure and the Design of Public
Support for Private Innovation. Research Policy, 4, 437-447.

5. Teubal M., 2002. What is the systems perspective to ITP, and how can we apply it to developing and newly industrialized economies? Journal of Evolutionary Economics, 12, 233-257.

6. Zhu P.F, and Xu W.M.,2003. The Government's Science and Technology Incentive Policy's Impact on R\&D Input and Patent Output of Large and Medium-sized Industrial Enterprises: An Empirical Study of Shanghai. Economic Research, 6, 45-53.

7. Mani S., 2002. Government, innovation, and technology policy: an international comparative analysis[M]. UK: Marston Book Services Limited, Abingdon. 